\title{
The Impacts of Temperature, Soil Type and Soil Herbicides on Seed Germination and Early Establishment of Common Milkweed (Asclepias syriaca L.)
}

\author{
Ljiljana RADIVOJEVIC ${ }^{1}$, Marija SARIC-KRSMANOVIC ${ }^{1}$, Jelena GAJIC \\ UMILJENDIC $^{1 *}$, Dragana BOZIC ${ }^{2}$, Ljiljana SANTRIC ${ }^{1}$
}

\author{
IInstituteofPesticidesandEnvironmentalProtectiom,Banatska31b,11080Zemum,Belgrade,Serbia;jiiljanaradivojeric@gmail.com;marijasaricmsaric@gmail.com; \\ pecikos@gmail.com (*correspondingauthor); lilijkasantric@gmail.com \\ ${ }^{2}$ University of Belgrade, Faculty of Agriculture, Nemanjina 6, 11080Zemum, Belgrade, Serbia; dbozic@agrif.bg.ac.rs
}

\begin{abstract}
The effects of different temperatures $\left(20^{\circ} \mathrm{C}, 25^{\circ} \mathrm{C}, 30^{\circ} \mathrm{C}, 35^{\circ} \mathrm{C}\right.$ and photoperiod $26^{\circ} \mathrm{C} / 21^{\circ} \mathrm{C}$ ), types of soil (sand and loam) and soil herbicides (oxyfluorfen, terbuthylazine and mesotrione) on seed germination percentage, germination rate, as well as seedling length and weight of common milkweed (Asclepias syriaca L.) were examined. Over a period of ten days, germinated seeds were counted daily, and seedling length and weight were measured on the final day and germination rate calculated. The results indicated that temperature was the factor that significantly affected the percentage of germinated seeds of common milkweed, seedling length and germination rate, while it had less influence on seedling weight. The results showed that the alternating day $/$ night temperature of $26^{\circ} \mathrm{C} / 21^{\circ} \mathrm{C}$ also had a significant impact as the percentage of germinated seeds was the highest at that temperature on both soil types (sand: 71.3\%; loam: 61.3\%). Data regarding the herbicides tested (oxyfluorfen, terbuthylazine and mesotrione) showed decreasing germination percentage and seedling length with increasing herbicide concentrations on both soil types. Their effect was weakest on seedling weight. Tested herbicides are usable in control of common milkweed at the stages of germination and early establishment.
\end{abstract}

Keywords: loam, mesotrione, oxyfluorfen, sand, terbuthylazine, weed

\section{Introduction}

Common milkweed (Asclepias syriaca L.) originates in Central and North America, and is most widespread in southern parts of Canada (Bhowmik and Bandeen, 1976). It was introduced in Europe at the beginning of the $19^{\text {th }}$ century and is now present in many South and Central European countries (Tutin et al., 1972) and countries in Serbia's neighbourhood (e.g. Hungary, Romania, Slovakia, Croatia, which have also included the species on their lists of invasive weeds) (Csontos et al., 2009; Hulina, 2010; Szatmari, 2012; Paukova et al., 2013). Distribution and frequency of common milkweed in anthropogenic habitats in Serbia (various types of crops and ruderal habitats in urban and rural areas) have been researched by Malidza et al. (2006) and Vrbnicanin et al. (2008) and they detected its presence in $15 \%$ of the assessed $10 \times 10 \mathrm{~km}$ squares on the UTM (Universal Transverse Mercator) grid.

Common milkweed is a perennial species with a large habit ( $2 \mathrm{~m}$ high), opposite and elliptic leaves, and flowers grouped in umbellate inflorescences. The fruit is a follicle covered with hairy worls. Each plant has around 25 follicles, and each follicle some 300 seeds (Gold and Shore, 1995). Common milkweed has adapted to a wide range of climatic and edaphic conditions. It grows well in moderate, humid and dry habitats, as well as in poor and sandy soils. In America it inhabits various types of soils but mostly the very dry type of loam (Phippen, 2007). Some researchers (Yenish et al., 1997; Hartzler and Buhler, 2000; Csontos et al., 2009) have found that the occurrence of common milkweed depends on neighbouring crops, as well as the type of soil. Common milkweed relative frequency has been found to exceed $70 \%$ in soybean, oat and sorghum crops, while it was considerably lower in maize, wheat and alfalfa crops (36, 28 and $6 \%$, respectively). While it made $70 \%$ and $51 \%$ along railway tracks and roadsides, it only accounted for $14 \%$ in meadows (Cramer and Burnside, 1982). In Serbia common milkweed is widespread along field edges, roadsides, embankments and railway tracks throughout Vojvodina province (North Serbia) and, in recent years it has been increasingly observed inside field crops (Malidza et al., 2006; Vrbnicanin et al., 2008).

Species invasions are a principal component of global change, causing large losses in biodiversity as well as economic damage (D'Antonio et al., 2001). Large economic impacts are also associated with many invasive species, which can provoke agricultural losses (Andow et al., 1990). Knowledge about germination would be very helpful for understanding the potential of common milkweed species for spread and invasiveness. Additionally, weeds emergence patterns dictate the extent to which herbicides and nonchemical methods must remain effective to minimize deleterious impacts on crop yield and quality (Norsworthy and Oliveira, 2007). Predicting the 
292

start and the duration of early establishment of seedling can contribute to taking better common milkweed control decisions (Berti et al., 1996) and facilitate optimal timing of control practices (Grundy, 2003). Results about effects of environmental factors on germination and early establishment can be very useful in that context. Several environmental factors, such as temperature, light, $\mathrm{pH}$ and soil moisture, are known to affect seed germination (Chauhan et al., 2006; Nandula et al., 2006). Many studies have shown these factors have variable effects on different populations of the same species (Beckstead et al., 1996; Milberg and Andersson, 1998). Although effects of different factors (Zimmerman and Weis, 1983; Norsworthy and Oliveira, 2007), including temperature (Norsworthy and Oliveira, 2007), on common milkweed germination were studied, to our knowledge there is no information about the effect of environmental factors on germination of common milkweed from Balkan Peninsula. As it is well known that one of the most important factors which affect seed germination and early establishment of seedlings is temperature, the objective of this research was to determine the effects of different temperatures on common milkweed seed germination and seedlings length and weight.

According to our knowledge, there are no reports on the effect of use of the soil herbicides (oxyfluorfen, terbuthylazine and mesotrione) on this invasive weed species. This kind of investigation could be helpful for better understanding of weed suppression measures in the field, which is necessary for establishing the best strategies for weed control.

Therefore, the objectives of this research were to: (1) examine the effects of different temperatures and (2) test the effects of soil herbicides on seed germination and early establishment of common milkweed seedlings on different types of soil.

\section{Materials and Methods}

Tests of temperature and soil type effects on seed germination and early establishment of common milkweed

Common milkweed seeds were collected at Tavankut (North Serbia, W 7382 591, E 5098 903, n.v. 102 m) in September of 2012. The seeds were cleaned and stored in the laboratory at a temperature of 20 to $22{ }^{\circ} \mathrm{C}$. All tests were conducted on two types of soil. The first soil, sampled from a location at Zemun Polje (Serbia), was a loamy soil ( $\mathrm{pH} 7.17$, organic matter $3.96 \%$, sand $49.80 \%$, silt $33.40 \%$, clay $16.80 \%$ ), medium calcareous, weakly alkaline and highly humic, rich in total nitrogen and well-supplied with available phosphorus and potassium. The other soil type was sampled at the location Tavankut (North Serbia), and its texture was sandy ( $\mathrm{pH} 7.63$, organic matter $0.91 \%$, sand $91.44 \%$, silt $1.32 \%$, clay $7.24 \%$ ), it was medium calcareous, medium alkaline and very weakly humic with moderate total nitrogen content and high supplies of available phosphorus and potassium.

The following temperatures were tested: $20^{\circ} \mathrm{C}, 25^{\circ} \mathrm{C}, 30^{\circ} \mathrm{C}$ and $35^{\circ} \mathrm{C}$. Twenty seeds were placed into each Petri dish containing $60 \mathrm{~g}$ of soil substrate (sand or loam), and $20 \mathrm{ml}$ of distilled water was added to each dish before leaving them in an incubator (Binder CE) in the dark. All the dishes were sealed with parafilm to avoid evaporation. All trial variants were performed in four replications and the trial was repeated twice. The same procedure was used for testing germination of common milkweed seeds under white light illumination in a climate room. The conditions included: $14 \mathrm{~h} / 10 \mathrm{~h}$ photoperiod, $26^{\circ} \mathrm{C} / 21^{\circ} \mathrm{C}$ temperature, 60 to $70 \%$ humidity and $300 \mu \mathrm{E} \mathrm{m}^{-2} \mathrm{~s}^{-1}$ light intensity. Distilled water was regularly added to maintain soil moisture. Germinated seeds were counted daily over a period of ten days, and the length and weight of seedlings were measured on the final day. Germination rate was calculated by Maguire's (1962) formula:

$$
\mathrm{M}=\mathrm{n}_{1} / \mathrm{t}_{1}+\mathrm{n}_{2} / \mathrm{t}_{2} \ldots+\mathrm{n}_{\mathrm{x}} / \mathrm{t}_{\mathrm{x}}
$$

where $n_{1}, n_{2}, \ldots n_{x}$ is the number of germinated seeds over $t_{1}$, $t_{2} \ldots t_{x}$ time elapsed since the start of the experiment expressed in days.

Tests of soil herbicides effects on seed germination and early establishment of common milkweed

The trial included following herbicides: oxyfluorfen (commercial product GALIGAN $240 \mathrm{EC}$, oxyfluorfen $240 \mathrm{gL}^{-1}$, Adama, Israel), terbuthylazine (commercial product RADAZIN TZ-500, terbuthylazine $500 \mathrm{~g} \mathrm{~L}^{-1}$, Herbos, Croatia) and mesotrione (commercial product CHIEF, mesotrione $100 \mathrm{~g} \mathrm{~L}^{-1}$, Adama, Israel). A series of solutions of specified concentrations calculated on the surface of the plastic tub were prepared, wherein the oxyfluorfen concentration of $960 \mathrm{~g}$ a.i. ha ${ }^{-1}$, terbuthylazine $750 \mathrm{ga.i}^{-1} \mathrm{a}^{-1}$ and mesotrione $120 \mathrm{ga.i}$. ha $\mathrm{a}^{-1}$ are the recommended field rates.

For each herbicide treatment a sample of sifted soil $(250 \mathrm{~g})$ was measured and placed in a thin layer on a plastic tub sized $23 \times 18 \mathrm{~cm}$. From previously prepared solutions of each herbicide concentration, $3 \mathrm{ml}$ were pipetted and transferred into a thinlayer chromatography sprayer which was connected to a compressor. The soil was treated uniformly over the surface, under constant pressure of 3 bars. Control samples were not treated with herbicides. After herbicide application, the soil was hand-mixed and transferred to Petri dishes. Twenty seeds and 20 $\mathrm{ml}$ of distilled water were added to each Petri dish, and the dishes were then placed in a climate chamber with the following conditions: photoperiod $14 \mathrm{~h} / 10 \mathrm{~h}$, temperature $26^{\circ} \mathrm{C} / 21^{\circ} \mathrm{C}$, humidity 60 to $70 \%$ and light intensity $300 \mu \mathrm{E} \mathrm{m}^{-2} \mathrm{~s}^{-1}$. Distilled water was regularly added to maintain soil moisture. The number of germinated seeds was counted on the $10^{\text {th }}$ day and the length and weight of seedlings were measured. All trial variants were performed in four replications and the trial was repeated twice.

\section{Data analysis}

Data were analysed by a two-factorial analysis of variance (ANOVA) using STATISTICA 8.0. software package. Normality distribution and homogeneity of variances were checked for all data using Kolmogorov-Smirnov and the Levene test. When $F$ values were statistically significant $(p<0.05)$ treatments were compared using the Fisher's Least Significant Difference (LSD) test. $\mathrm{ED}_{50}$ were calculated for each herbicide using BIOASSAY 97 software package.

\section{Results and Discussion}

Effects of temperature and soil type on seed germination and early establishment of common milkweed

The germination results obtained with seeds of common milkweed at different temperatures between 20 and $35^{\circ} \mathrm{C}$ are presented in Figure 1. The lowest germination percentage (sand: 19.4\%; loam: 16.3\%) was recorded at the lowest temperature of $20^{\circ} \mathrm{C}$. At $25^{\circ} \mathrm{C}$ and $35^{\circ} \mathrm{C}$, the percentage of germination ranged 
from $22.5 \%$ to $39.4 \%$ at both soil types, but it was higher on sandy than on loamy soil at both temperatures. The highest germination of $64.4 \%$ was found at temperature of $30{ }^{\circ} \mathrm{C}$ in sandy soil, and $51.9 \%$ in loamy soil. However, our data showed that photoperiod temperatures of $26^{\circ} \mathrm{C} / 21^{\circ} \mathrm{C}$ are the optimal for germination of common milkweed seeds. The percentage of germination under such conditions, on both soil types, was highest, precisely $71.3 \%$ on sand and $61.3 \%$ on loam. Statistical analysis showed that temperature $(\mathrm{F}=81.92, \mathrm{p}=0.000000)$ and type of soil $(\mathrm{F}=18.50, \mathrm{p}=0.000054)$ had highly significant influence on the germination of common milkweed seeds.

In a similar way, Farmer et al. (1986) tested germination of several populations of common milkweed on different substrates [filter paper, sand, clay, peat, peat-clay $(1: 1)$, peat-sand $(1: 1)$ ] and temperatures $\left(20\right.$ to $\left.40^{\circ} \mathrm{C}\right)$ and concluded that temperature regime was most important to seed germination success, though substrate type did influence germination percentage to some degree. The greatest germination percentage (59\% average over all substrates) was obtained with an alternating $20^{\circ} \mathrm{C}(16 \mathrm{~h}), 30$ ${ }^{\circ} \mathrm{C}(8 \mathrm{~h})$ temperature regime. At a constant temperature of 30 ${ }^{\circ} \mathrm{C}$, germination was lower (32\% average over all substrates). Furthermore, these authors, found a greatest percentage of germination on clay and peat-clay, followed by filter paper, sand, peat and peat-sand. Conversely, in our studies, the highest percentage of germination at all temperatures was recorded in sandy soil which could be explained with greater water availability and/or a better seed-soil contact.

Baskin and Baskin (1977) reported that after nine weeks of stratification, regardless of whether seeds were in light or darkness during and/or after stratification, seeds germinated to $94 \%$ or more at $35 / 20{ }^{\circ} \mathrm{C}$ and $30 / 15^{\circ} \mathrm{C}$, to $70 \%$ or more at $20 / 10{ }^{\circ} \mathrm{C}$ and to only $0.7 \%$ at $15 / 6{ }^{\circ} \mathrm{C}$. Evetts and Burnside (1972) concluded that maximum germinating temperatures were $35^{\circ} \mathrm{C}$ or $35-40^{\circ} \mathrm{C}$, while Bhowmik (1978) revealed in his experiment that maximum seedling emergence occurred at $27{ }^{\circ} \mathrm{C}$. This relatively high temperature requirement for germination is probably one reason why this species emerges later in the growing season than many other weed species.

The effects of different temperatures and soils on seedling length, seedling weight, and germination rate of common milkweed seeds in our experiment are presented in Table 1. There is no available data to our knowledge about the effect of temperatures and soil type on early establishment of common milkweed, but our research confirmed that those factors have a significant $(p<0.05)$ effect on the seedlings length (temperature: $\mathrm{F}=17.20, \mathrm{p}=0.000000$; soil type: $\mathrm{F}=16.56, \mathrm{p}=0.000122$ ). Generally, for seedling weight, differences between soil type were present, but were not significant $(\mathrm{p}>0.05)$ while the temperature was significant $(\mathrm{F}=2.60, \mathrm{p}=0.043304)$ parameter. The longest seedlings $(7.85 \mathrm{~cm})$ were found on sandy soil at 30 ${ }^{\circ} \mathrm{C}$ temperature, while the average seedling length on loam under the same temperature was $4.70 \mathrm{~cm}$. Seedling length at $35^{\circ} \mathrm{C}$ and day/night temperatures of $26{ }^{\circ} \mathrm{C} / 21{ }^{\circ} \mathrm{C}$ were almost the same while seedlings were shorter at lower temperatures $\left(25^{\circ} \mathrm{C}\right.$ and 20 $\left.{ }^{\circ} \mathrm{C}\right)$. Similarly, seedlings had the greatest weight at $30^{\circ} \mathrm{C}$ on sandy soil $(0.07 \mathrm{~g})$, and slightly lower on loam (0.06 g), while their weights were almost the same on both soils at the other temperatures.

Germination rates, which represents the sum of germinations per day, depended significantly on temperature $(\mathrm{F}$ $=50.22, \mathrm{p}=0.000000)$ and soil type $(\mathrm{F}=16.76, \mathrm{p}=0.000112)$. The highest germination rates were observed under day/night temperatures of $26^{\circ} \mathrm{C} / 21^{\circ} \mathrm{C}$ (sand: 14.25 ; loam: 11.30), and 30 ${ }^{\circ} \mathrm{C}$ (sand: 12.86; loam: 10.91), while that parameter had lower values at all other temperatures $\left(20^{\circ} \mathrm{C}, 25^{\circ} \mathrm{C}\right.$ and $\left.35^{\circ} \mathrm{C}\right)$.

\section{Effects of soil herbicides on seed germination and early establishment of common milkweed}

Effects of different herbicides and soil type on seedling length, seedling weight and germination percentage of common milkweed seeds are presented in Table 2. A higher percentage of germination was overall determined in the sandy soil. In this soil type, oxyfluorfen was proved to be the most effective, thus, at recommended field rate concentration $\left(960 \mathrm{~g} \mathrm{ha}^{-1}\right)$ inhibition of germination (comparing with control) was the highest (36.1\%). The treatment with mesotrione at recommended field rate (120 $\mathrm{g} \mathrm{ha}^{-1}$ ) caused the reduction of germination of $22.2 \%$, while the lowest germination inhibition $(20.8 \%)$ was within the treatment

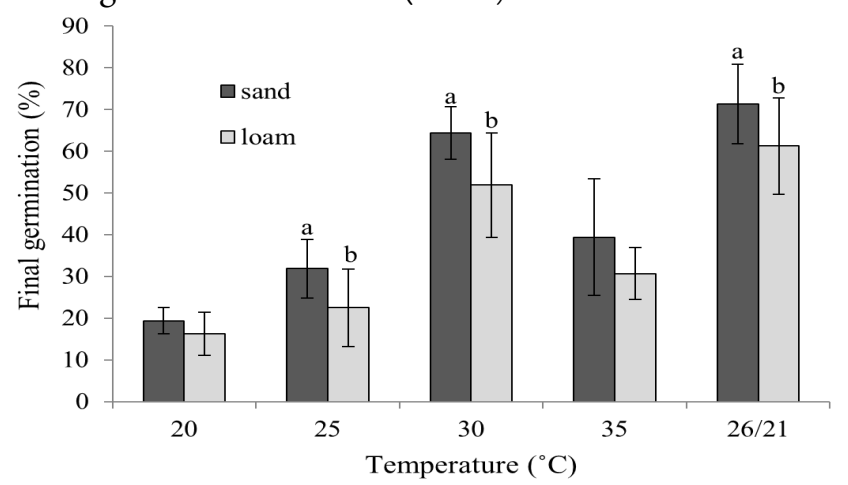

Fig. 1. Final percentage of seed germination (\%) of common milkweed at different temperatures and soil type $(\mathrm{P}<0.05$, LSD test $-a, b-$ differences between treatments and soil)

Table 1. Effects of different temperatures and soil type on seedling length $(\mathrm{cm})$, seedling weight $(\mathrm{g})$ and germination rate $\left(\right.$ no. day $\left.{ }^{-1}\right)$ of common milkweed seeds

\begin{tabular}{|c|c|c|c|c|}
\hline Treatment & Soil & Seedling length $(\mathrm{cm})$ & Seedling weight (g) & Germination rate (no. day $\left.{ }^{-1}\right)$ \\
\hline \multirow{2}{*}{$20{ }^{\circ} \mathrm{C}$} & sand & $2.20 \pm 0.83$ & $0.06 \pm 0.01$ & $4.15 \pm 0.52$ \\
\hline & loam & $1.96 \pm 0.77$ & $0.04 \pm 0.01$ & $3.65 \pm 0.76$ \\
\hline \multirow{2}{*}{$25^{\circ} \mathrm{C}$} & sand & $5.70 \pm 2.69$ & $0.05 \pm 0.01$ & $7.56 \pm 1.70 \mathrm{a}$ \\
\hline & loam & $4.63 \pm 1.23$ & $0.04 \pm 0.01$ & $5.05 \pm 1.66 \mathrm{~b}$ \\
\hline \multirow{2}{*}{$30{ }^{\circ} \mathrm{C}$} & sand & $7.85 \pm 1.18$ a & $0.07 \pm 0.01$ & $12.86 \pm 1.68$ \\
\hline & loam & $4.70 \pm 1.10 \mathrm{~b}$ & $0.06 \pm 0.02$ & $10.91 \pm 2.79$ \\
\hline \multirow{2}{*}{$35^{\circ} \mathrm{C}$} & sand & $6.72 \pm 1.23 \mathrm{a}$ & $0.06 \pm 0.01$ & $9.23 \pm 3.36$ \\
\hline & loam & $4.25 \pm 0.58 \mathrm{~b}$ & $0.05 \pm 0.02$ & $7.50 \pm 2.16$ \\
\hline \multirow{2}{*}{$26^{\circ} \mathrm{Cday} / 21^{\circ} \mathrm{Cnight}$} & sand & $6.15 \pm 1.87$ & $0.04 \pm 0.01$ & $14.25 \pm 2.19 \mathrm{a}$ \\
\hline & loam & $5.23 \pm 0.70$ & $0.04 \pm 0.01$ & $11.30 \pm 2.55 \mathrm{~b}$ \\
\hline
\end{tabular}


294

with terbutilazine at its recommended field rate $\left(750 \mathrm{~g} \mathrm{ha}^{-1}\right)$. Similar was in the loam soil, as the highest inhibition of germination was as well obtained in soil treated with oxyfluorfen (32.2\%). However, in this soil type, treatment with terbutilazine was the next most effective one, leading to germination reduction up to $25.4 \%$, while significantly lower inhibition of germination was recorded in the treatment with mesotrione (3.4\%).

The length of common milkweed seedlings in both soils decreased as the herbicide concentrations increased (Table 2). In the sandy soil, mesotrione was the most effective concerning the reduction of the seedling length, as in the treatment with recommended field rate of this herbicide, inhibition of this parameter was 61\%. Lower inhibitions of the seedling lengths were obtained in the treatment with oxyfluorfen and terbutilazine ( 52.2 and $49.9 \%$ respectively). On the other hand, in loamy soil the lowest inhibition of seedling length was recorded in the treatment with mesotrione (54\%), while oxyfluorfen and terbutilazine were proved to be more effective in the reduction of this parameter, with seedling length inhibition of 57.8 and $56.3 \%$ respectively.

The calculated $\mathrm{ED}_{50}$ values showed that the lower application rates of oxyfluorfen caused lower seedling length on loam $\left(\mathrm{ED}_{50}\right.$ $=1,000.33$ ) than on sand $\left(\mathrm{ED}_{50}=1,061.40\right)$ (Fig. 2). Conversely, lower concentrations of terbuthylazin caused lower seedling length on sand $\left(\mathrm{ED}_{50}=737.63\right)$, while on loam the calculated $\mathrm{ED}_{\text {so value was }}$ 797.82. Also, in mesotrione treatments, the lower application rates caused lower seedling length on sand $\left(\mathrm{ED}_{50}=\right.$ 108.22) than on loam $\left(\mathrm{ED}_{50}=138.46\right)$.

Generally, tested herbicides were the least effective in the reduction of the seedling weight, as the weight of seedlings in all trial variants ranged from 0.02 to $0.04 \mathrm{~g}$ (Table 2).

Overall, based on the obtained results, it could be concluded that the effectiveness of all three tested herbicides on seed germination and early establishment of common milkweed in the loamy soil were nearly the same. However, in the sandy soil mesotrione was proved to be more effective than other two herbicides. This was probably due to physico-chemical properties of mesotrione (i.e. its high water solubility of $15 \mathrm{~g} \mathrm{~L}^{-1}$ ) coupled with physico-chemical properties of sandy soil (low organic matter content $0.91 \%$ and high sand content $91.44 \%$ ), which enable this herbicide to be highly available for the seedlings of common milkweed.
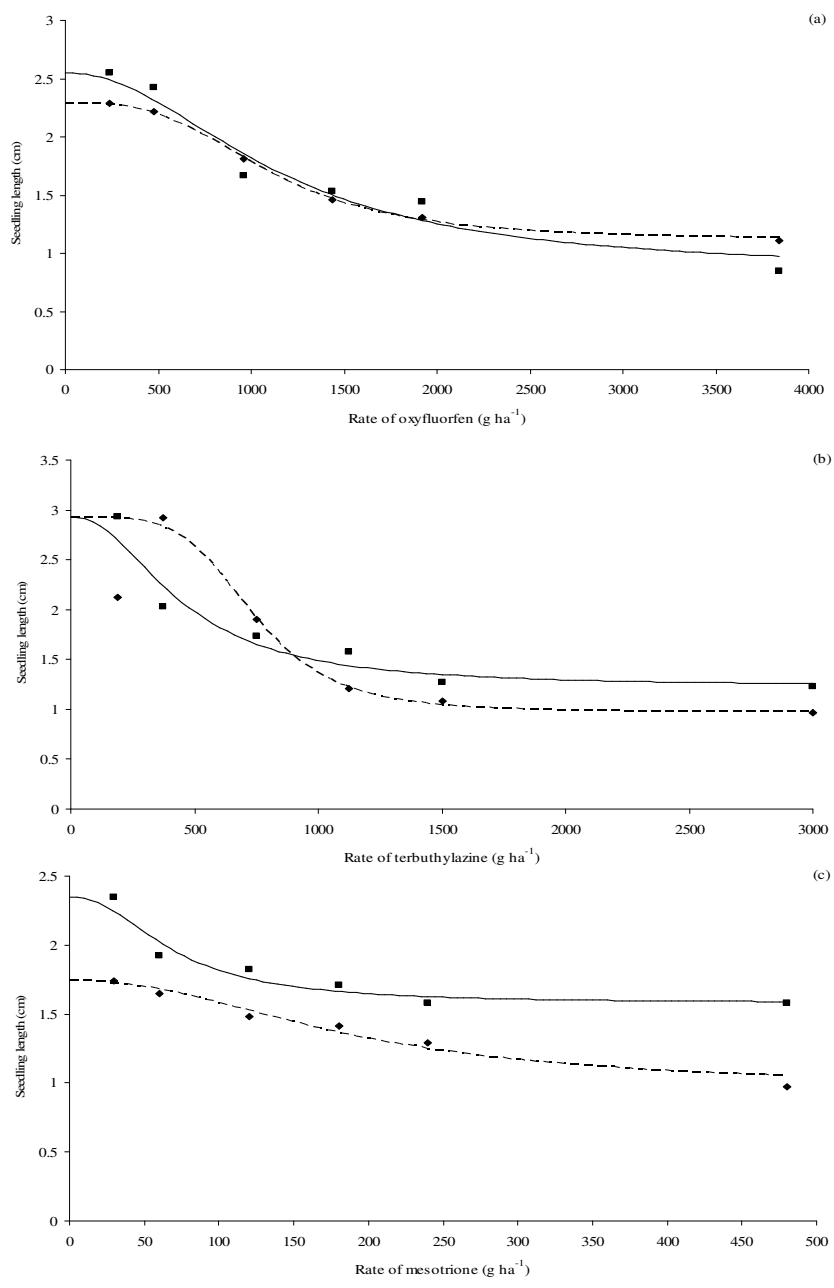

Fig.2. Responses of common milkweed to increasing rates of oxyfluorfen (a), terbuthylazine (b) and mesotrione (c) based on seedling length in loam (-) and sand $(---)$

Table 2. Effects of different herbicides and soil type on seedling lenght $(\mathrm{cm})$, seedling weight $(\mathrm{g})$ and germination (\%) of common milkweed seeds

\begin{tabular}{|c|c|c|c|c|c|c|c|}
\hline & \multirow{2}{*}{$\frac{\text { Concentration }}{\text { g a.s. }^{-1}}$} & \multicolumn{2}{|c|}{ Seedling lenght $(\mathrm{cm})$} & \multicolumn{2}{|c|}{ Seedling weight $(\mathrm{g})$} & \multicolumn{2}{|c|}{ Germination (\%) } \\
\hline & & loam & sand & loam & sand & loam & sand \\
\hline \multirow{7}{*}{ 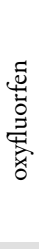 } & control & $3.96 \pm 0.55$ & $3.79 \pm 0.17$ & $0.04 \pm 0.01$ & $0.05 \pm 0.01$ & 38.9 & 45.0 \\
\hline & 240 & $2.55 \pm 0.69$ & $2.29 \pm 0.68$ & $0.03 \pm 0.01$ & $0.03 \pm 0.01$ & 34.4 & 37.5 \\
\hline & 480 & $2.42 \pm 0.25$ & $2.22 \pm 0.39$ & $0.04 \pm 0.01$ & $0.03 \pm 0.01$ & 36.9 & 38.8 \\
\hline & 960 & $1.67 \pm 0.90$ & $1.81 \pm 0.73$ & $0.03 \pm 0.01$ & $0.03 \pm 0.01$ & 25.0 & 28.8 \\
\hline & 1440 & $1.53 \pm 0.49$ & $1.46 \pm 0.40$ & $0.03 \pm 0.01$ & $0.03 \pm 0.01$ & 23.8 & 25.6 \\
\hline & 1920 & $1.44 \pm 0.32$ & $1.31 \pm 0.32$ & $0.03 \pm 0.01$ & $0.02 \pm 0.01$ & 18.8 & 21.9 \\
\hline & 3840 & $0.85 \pm 0.52$ & $1.11 \pm 0.60$ & $0.02 \pm 0.01$ & $0.02 \pm 0.01$ & 16.3 & 18.8 \\
\hline \multirow{7}{*}{ 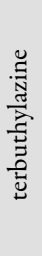 } & control & $3.96 \pm 0.55$ & $3.79 \pm 0.17$ & $0.04 \pm 0.01$ & $0.05 \pm 0.01$ & 38.9 & 45.0 \\
\hline & 187.5 & $2.93 \pm 0.46$ & $2.12 \pm 0.43$ & $0.04 \pm 0.01$ & $0.03 \pm 0.01$ & 33.1 & 42.5 \\
\hline & 375 & $2.03 \pm 0.16$ & $2.92 \pm 0.32$ & $0.03 \pm 0.01$ & $0.02 \pm 0.01$ & 29.4 & 40.6 \\
\hline & 750 & $1.73 \pm 0.34$ & $1.90 \pm 0.22$ & $0.03 \pm 0.01$ & $0.02 \pm 0.01$ & 27.5 & 35.6 \\
\hline & 1125 & $1.58 \pm 0.20$ & $1.21 \pm 0.09$ & $0.03 \pm 0.01$ & $0.02 \pm 0.01$ & 27.5 & 39.3 \\
\hline & 1500 & $1.27 \pm 0.18$ & $1.08 \pm 0.26$ & $0.03 \pm 0.01$ & $0.02 \pm 0.01$ & 25.6 & 27.5 \\
\hline & 3000 & $1.23 \pm 0.22$ & $0.97 \pm 0.10$ & $0.02 \pm 0.01$ & $0.02 \pm 0.01$ & 23.1 & 20.6 \\
\hline \multirow{7}{*}{ 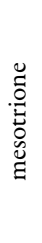 } & control & $3.96 \pm 0.55$ & $3.79 \pm 0.17$ & $0.04 \pm 0.01$ & $0.05 \pm 0.01$ & 38.9 & 45.0 \\
\hline & 30 & $2.35 \pm 0.40$ & $1.74 \pm 0.54$ & $0.04 \pm 0.01$ & $0.03 \pm 0.01$ & 39.4 & 40.6 \\
\hline & 60 & $1.92 \pm 0.10$ & $1.65 \pm 0.38$ & $0.03 \pm 0.01$ & $0.02 \pm 0.01$ & 38.1 & 36.9 \\
\hline & 120 & $1.82 \pm 0.39$ & $1.48 \pm 0.03$ & $0.03 \pm 0.01$ & $0.02 \pm 0.01$ & 35.3 & 35.0 \\
\hline & 180 & $1.71 \pm 0.15$ & $1.41 \pm 0.59$ & $0.03 \pm 0.01$ & $0.03 \pm 0.01$ & 34.4 & 32.5 \\
\hline & 240 & $1.58 \pm 0.25$ & $1.29 \pm 0.50$ & $0.03 \pm 0.01$ & $0.04 \pm 0.02$ & 30.6 & 29.4 \\
\hline & 480 & $1.58 \pm 0.49$ & $0.97 \pm 0.47$ & $0.04 \pm 0.01$ & $0.02 \pm 0.01$ & 27.5 & 26.3 \\
\hline
\end{tabular}


There is a lack of literature data comparable with results obtained in this study, due to different methods used for investigation of herbicide efficiency on seed germination and early establishment of common milkweed. This research was conducted in laboratory conditions, however the results may serve as a guideline to help growers to select the most efficacious herbicide for limiting establishment of this invasive species, especially considering that those three tested soil herbicides are already in intensive usage in plant protection in our country.

\section{Conclusions}

The results of our studies indicate that common milkweed has the ability to germinate under a broad range of temperatures. Obtained data showed that photoperiod temperatures of 26 ${ }^{\circ} \mathrm{C} / 21^{\circ} \mathrm{C}$ are the optimal for germination of common milkweed seeds. Effects of temperature are more expressed on seedlings length and seed germination than on seedlings weight. Also, the results showed that the herbicides oxyfluorfen, terbuthylazin and mesotrione are usable in control of common milkweed at the stages of germination and early establishment.

\section{Acknowledgements}

This work was supported by the Ministry of Education, Science and Technological Development of the Republic of Serbia (Grant No. TR31043 and III46008).

\section{References}

Andow DA, Kareiva PM, Levin SA, Okubo A (1990). Spread of invading organisms. Landscape Ecology 4:177-188.

Baskin JM, Baskin CC (1977). Germination of common milkweed (Asclepias syriacaL.) seeds. Bulletin of the Torrey Botanical Club 104:167-170.

Beckstead J, Meyer SE, Allen PS (1996). Bromus tectorum seed germination: between -population and between - year variation. Canadian Journal of Botany 74:875-882.

Berti A, Dunan C, Sattin M, Zanin P, Wesra G (1996). A new approach to determine when to control weeds. Weed Science 44:496-503.

Bhowmik PC, Bandeen JD (1976). The biology of Canadian weeds. Canadian Journal of Plant Science 56:579-589.

Bhowmik PC (1978). Germination, growth and development of common milkweed. Canadian Journal of Plant Science 58:493-498.

Chauhan BS, Gil G, Preston C (2006). Factors affecting seed germination of annual sowthistle (Sonchus oleraceus) in Southern Australia. Weed Science 54:854-860.

Cramer GL, Burnside OC (1982). Distribution and interference of common milkweed (Asclepias syriaca) in Nebraska. Weed Science 30:385-388.

Csontos P, Bózsing E, Cseresnyés I, Penksza K (2009). Reproductive potential of the alien species Asclepias syriaca (Asclepiadaceae) in rural landscape. Polish Journal of Ecology 57:383-388.

D’Antonio C, Meyerson LA, Denslow J (2001). Exotic species and conservation. In: Soulé ME, Orians GH (Eds). Conservation Biology: Research Priorities for the Next Decade. Island, Washington DC USA pp 59-80.

Evetts LL, Burnside OC (1972). Germination and seedling development of common milkweed and other species. Weed Science 20:371-378.
Farmer JM, Price SC, Bell CR (1986). Population, temperature, and substrate influences on common milkweed (Asclepiassyriaca L.) seed germination. Weed Science 34:525-528.

Gold JJ, Shore JS (1995). Multiple paternity in Asclepias syriaca using a paired-fruit analysis. Canadian Journal of Botany 73:1212-1216.

Grundy AC (2003). Predicting weed emergence: a review of approaches and future challenges. Weed Research 43:1-11.

Hartzler RG, Buhler DD (2000). Occurrence of common milkweed (Asclepias syriaca) in cropland and adjacent areas. Crop Protection 19:363-366.

Hulina N (2010). "Planta Hortifuga" in flora of the continental part of Croatia. Agriculturae Conspectus Scientificus 75:57-65.

Maguire J (1962). Speed of germination aid in selection and evaluation for seedling emergence and vigour. Crop Science 2:176-177.

Malidza G, Vrbnicanin S, Gavric M (2006). Common Milkweed adventive invasion weed species in Serbia and possibility of control. In: Proceedings of the 4th European Conference on Biological Invasions - NEOBIOTA From Ecology to Conservation, Vienna, Austria pp 187.

Milberg P, Andersson L (1998). Does cold stratification level out differences in seed germinability between population? Plant Ecology 134:225-234.

Nandula VK, Eubank TW, Poston DH, Koger CH, Reddy KN (2006). Factors affecting germination of horseweed (Conyza canadensis). Weed Science 54:898-902.

Norsworthy JK, Oliveira MJ (2007). Light and temperature requirements for common cocklebur (Xanthium strumarium) germination during after-ripening under field conditions. Weed Science 55:227-234.

Paukova Z, Kaderova V, Bakay L (2013). Structure and population dynamics of Asclepias syriaca $\mathrm{L}$. in the agricultural land. Agriculture 59:161-166.

Phippen BW (2007). Production variables affecting follicle and biomass development in common milkweed. In: Janikand J, Whipkey A (Eds). Issues in new crops and new uses. ASHS Press, Alexandria Virginia USA pp 82-88.

Szatmari PM (2012). Alien and invasive plants in Carei Plain Natural Protected Area, Western Romania: Impact on natural habitats and conservation implications. South Western Journal of Horticulture, Biology and Environment 3:109-120.

Tutin TG, Heywood VH, Burges NA, Moore DM, Valentine DH, Walters SM, Webb DA (1972). Flora Europaea III. Cambridge, UK: Cambridge University Press.

Vrbnicanin S, Malidza G, Stefanovic, S., Elezovic I, Stankovic-Kalezic R, Jovanovic-Radovanov K, ... Gavric M (2008). Mapping of invasive non-native weed species in Serbia. In: Book of Abstracts of Meeting Invasive Species, Osijek, Croatia pp 23.

Yenish JP, Fry TA, Durgan BR, Wyse DL (1997). Establishment of common milkweed (Asclepias syriaca) in corn, soybean, and wheat. Weed Science 45:44-53.

Zimmerman JK, Weis IM (1983). Fruit size variation and its effects on germination and seedling growth in Xanthium strumarium. Canadian Journal of Botany 61:2309-2315. 